\title{
Evidence for dissociable motor skills in Huntington's disease patients
}

\author{
DANIEL B. WILLINGHAM \\ University of Virginia, Charlottesville, Virginia \\ and \\ WALTER J. KOROSHETZ \\ Massachusetts General Hospital, Boston, Massachusetts
}

\begin{abstract}
It has been proposed that the striatum is critical for acquiring new motor skills. Previous experiments have shown that patients with striatal dysfunction are impaired in acquiring new motor skills, but the tasks have always used stimuli that move in a repeating, predictable pattern. Four experiments showed that Huntington's disease (HD) patients are impaired in learning such skills, but can learn at a normal rate skills that require the learning of a new perceptual-motor mapping. HD patients were impaired in learning a repeating motor sequence in a keypressing task. When the repeating sequence was removed and the stimulus-response mapping was made spatially incompatible, HD patients showed normal learning. HD patients learned a maze task when responding with a computer mouse but were impaired on a variation that required key. press responses. Control subjects showed no sensitivity to the repetitive sequence of movements in the mouse version, but part of their knowledge was sequence based in the keypress version. The neural basis of motor skill components is discussed.
\end{abstract}

Normal performance on different memory tests relies on the integrity of different neural structures. For example, medial temporal lobe, diencephalic, and basal forebrain structures are clearly critical for normal recognition or recall of facts or events (Squire \& Zola-Morgan, 1991); damage to one or more of these structures results in amnesia. Performance on other memory tests does not rely on these structures; amnesic patients show normal learning of motor skills (Brooks \& Baddeley, 1976; Corkin, 1968; Milner, 1962; Nissen, Willingham, \& Hartman, 1989) as well as other types of skill (Benzing \& Squire, 1989; Cohen \& Squire, 1980; Shimamura, 1986). Given that motor skills are not impaired in the face of amnesia, they would seem not to rely on the medial temporal lobe, basal forebrain, or diencephalon. What structures, then, support their performance?

\footnotetext{
This project was supported by funds from NSF Grants BNS 86-09232 and BNS 88-21029, the Harvard University Department of Psychology, and the Richard Hodgson Memorial fund. This work served as partial fulfillment of the requirements for a doctoral degree at Harvard University. Portions of this work were presented at the annual meeting of the Society for Neuroscience, St. Louis, 1990. The authors are indebted to Scott Bradner, Josh Hurwitz, Kris Kirby, Jonathan Kolodny, and Warren Willingham for technical support and to William K. Estes, Maggie Keane, Stephen Kosslyn, and Bill Millberg for advice. We also thank two anonymous reviewers for helpful comments on the manuscript. We especially offer thanks to the Huntington's patients who were so eager to cooperate, and to those who support the Massachusetts General Hospital Huntington's Disease Research Center, with which W.J.K. is affiliated. Correspondence may be sent to D. B. Willingham, Department of Psychology, Gilmer Hall, University of Virginia, Charlottesville, VA 22903 (e-mail: dbw8m@virginia.edu).
}

Motor skills may be defined as those that entail the improvement of motor coordination, timing, or perceptualmotor integration for their expression, and that are not readily expressed verbally. The chief candidate for the substrate of motor skills has been the striatum (Mishkin, Malamut, \& Bachevalier, 1984). In support of this hypothesis, patients with striatal abnormalities often show impairments in learning new motor skills. Knopman and Nissen (1991) found that Huntington's disease (HD) patients were impaired on a serial response time (SRT) task, in which a repeating sequence was embedded in a fourchoice response time (RT) task. Soliveri, Brown, Jahanshahi, and Marsden (1992) asked Parkinson's disease (PD) patients to practice buttoning buttons on a cardigan and concluded that the patients required more practice to learn the skill, although the interpretation was complicated by control subjects' apparent asymptotic performance midway through practice.

Many studies have examined performance on tracking tasks in which the target moves in a repeating, predictable pattern. Patients with HD or PD show impaired learning on the pursuit rotor task (Harrington, Haaland, Yeo, \& Marder, 1990; Heindel, Butters, \& Salmon, 1988; Heindel, Salmon, Shults, Walicke, \& Butters, 1989). PD patients are also impaired on other tracking tasks with a predictable track (Flowers, 1978; Frith, Bloxham, \& Carpenter, 1986).

Thus there are few studies of motor skill in patients with striatal dysfunction, and the range of tasks has been surprisingly small; all the tasks require subjects to perform the same movement across trials, and learning is inferred if these movements are made more quickly or accurately 
with practice. Not all skills entail a repetitive sequence of movements, however. One might learn a new mapping between visual stimuli and the appropriate motor response, as in mirror tracing. There is some evidence that PD patients are able to learn new stimulus-response mappings, as in a prism adaptation task (Weiner, Hallett, \& Funkenstein, 1983). PD patients also seem able to learn an incompatible stimulus-response mapping in a button pushing task (Robertson \& Flowers, 1990), although the measure in this experiment was not the speed with which the response could be made but simply correct performance, and therefore this measure may not have been very sensitive.

We tested HD patients on motor skills that require repetitive movements and on skills that require learning a new perceptual-motor mapping. We expected that HD patients would be impaired in the former but not in the latter.

In Experiment 1, we sought to replicate the results of Knopman and Nissen (1991), who found that HD patients were impaired in learning the SRT task. It is important to note that control subjects learn the sequence even though they report that they are unaware of any pattern in the task (Nissen \& Bullemer, 1987; Willingham, Nissen, \& Bullemer, 1989). HD patients show some impairment in memory measures that require conscious recollection (Butters, Wolfe, Granholm, \& Martone, 1986), so a task that requires conscious learning of a pattern would rely not simply on motor sequencing but on another process already known to be impaired in HD.

\section{GENERAL METHOD}

\section{Overview of Experiments}

The testing was divided into two 1- to 2-h sessions. In the first, subjects performed the four experiments. The same stimuli and responses were used in Experiments 1 and 2, but the mappings were different. We expected that the incompatible mapping would interfere with the compatible mapping. Therefore, all subjects performed Experiment 1 first and Experiment 2 last, with Experiments 3 and 4 in between; the order of Experiments 3 and 4 was randomly determined. For each experiment, subjects were eliminated from the analysis if their response times or accuracy scores were three standard deviations from the mean of the other subjects in their subject group.

In the second session, subjects performed the standardized neuropsychological tests described below. The HD patients, who tire more easily than control subjects, performed these sessions on different days.

\section{Apparatus}

All tests were conducted on an Apple Macintosh SE computer. The response boards measured $34.5 \times 23.5 \mathrm{~cm}$ and had four keys (Radio Shack 275 1566). On one board, the keys were arranged horizontally (the center-to-center distance was $4 \mathrm{~cm}$ ). On the other board, the four keys were arranged in a diamond (center-to-center distance of adjacent keys was $13 \mathrm{~cm}$ ).

\section{Subjects}

The HD subjects ( 5 males and 7 females) were recruited from the Massachusetts General Hospital Huntington's Disease Clinic. All subjects had been identified as having HD and had been assessed by one of us (W.J.K.), the criteria being positive family history and clinical symptoms. All patients were in the early stages of the disease: the average score on the Shoulson independence scale (Shoulson \& Fahn, 1979) was 10.2 (maximum = 13). From previous studies, we would expect that these patients would have striatal atrophy graded as 1 or 2 on a 4-point scale (Myers et al., 1988). All showed impaired fine motor control of the fingers and tongue, and most showed chorea. Their performance on standard neuropsychological tests was measured and is described below. At the time of testing, 9 of the patients were on medication: 3 on Haldol, 2 on imipramine, 2 on clonazepam, 1 on amitryptaline, and 1 on trazadone.

Healthy age-matched control subjects ( 5 males and 7 females) were recruited from the staff at Harvard University. An effort was also made to match the HD population in terms of age and education, and they were required to be in good health, as assessed by the Neurological Scale of the Medical History Inventory (National Institutes of Health, 1988).

\section{Neuropsychological Testing}

The results of the standardized neuropsychological tests are summarized in Table 1.

The patients were impaired on the Blessed Dementia Scale (Blessed, Tomlinson, \& Roth, 1968), an index of overall cognitive ability. They were also impaired in verbal memory, which was tested by asking them to remember a list of 16 words and requiring immediate recall. Four such trials were administered and the scores summed. There was no penalty for guessing.

Still, the patients' performance on other tests was good. They were unimpaired on the vocabulary subtest of the Wechsler Adult Intelligence Scale-Revised (WAIS-R) (Wechsler, 1981), which provides a general measure of verbal ability (Lezak, 1976). They also performed normally on two tests of visuospatial ability: the Block Design subtest of the WAIS, which requires subjects to use blocks to construct colored patterns that appear on cards, and the Benton Visual Retention Test, multiple-choice type (Benton, 1950), which

Table 1

Mean Performance on Neuropsychological Tests, by Subject Group

\begin{tabular}{|c|c|c|c|c|}
\hline \multirow[b]{3}{*}{ Measure } & \multicolumn{4}{|c|}{ Subject Group } \\
\hline & \multicolumn{2}{|c|}{ HD } & \multicolumn{2}{|c|}{ Control } \\
\hline & $M$ & $S D$ & $M$ & $S D$ \\
\hline Age & 43.7 & 13.7 & 48.7 & 15.3 \\
\hline Education & 12.8 & 2.8 & 13.4 & 1.8 \\
\hline Blessed Dementia Scale & $7.0^{*}$ & 2.1 & 1.5 & 2.0 \\
\hline Verbal long-term memory & $25.1 *$ & 6.9 & 42.0 & 9.4 \\
\hline Vocabulary subtest of WAIS & 43.2 & 14.1 & 51.7 & 9.8 \\
\hline Benton Visual Retention Test, multiple-choice type & 11.1 & 1.7 & 12.5 & 1.6 \\
\hline Block Design subtest of WAIS & 25.7 & 8.2 & 31.5 & 10.1 \\
\hline
\end{tabular}

Note-HD, Huntington's disease. ${ }^{*} p<.001$. 
requires one to recognize a complex pattern from among four choices after a very brief delay.

\section{EXPERIMENT 1}

\section{Method}

The three tasks in the SRT experiment were the SRT task, an interview, and a cued-recall task, called the generate task.

SRT task. The subject rested the index and middle finger of each hand on four keys arranged horizontally. An asterisk appeared in one of four corresponding positions on the computer screen, and the subject pushed the key directly below the asterisk as quickly as possible. If the subject pushed the wrong key, a tone sounded for $120 \mathrm{msec}$ and the subject continued to respond until a correct response was made. There was no feedback about response times. When the subject pushed the correct key, the asterisk was extinguished, there was a 250-msec pause, and the next asterisk appeared in a different position. The subject responded to that asterisk, whereupon a new asterisk appeared, and so on. The subject was instructed to respond as quickly as possible without making errors.

The asterisks appeared $1.5 \mathrm{~cm}$ from the bottom of the screen and $1.5,6.5,11.5$, and $16.5 \mathrm{~cm}$ from the left edge of the screen; at a viewing distance of $50 \mathrm{~cm}$, the visual angle between asterisks was $5.73^{\circ}$. To reduce confusion about the stimulus locations, a small dot was always visible just above each location.

Sixty stimulus presentations constituted a block, and each subject performed 10 blocks with a 30 -sec rest break between blocks. In the 1st and 10th block of trials, the asterisks appeared randomly, although an asterisk could not appear in the same position on consecutive trials. On Trial Blocks 2-9, the asterisks appeared in a repeating sequence of positions. With the four positions numbered from left to right as 1-4, the sequence was 231432413421 . All subjects saw the same repeating sequence and the same random sequence on the 1st and last blocks. The subjects were not told about the repeating sequence on Blocks 2-9, and nothing marked the beginning or end of the sequence, so the repeating sequence could appear to the subjects to be a continuous stream of randomly appearing asterisks.

Interview. After the subjects had completed the SRT task, they were asked a series of progressively more specific questions to assess their awareness of the repeating sequence. The questions appear in Table 2. If the subject mentioned nothing about a repeating sequence in responding to the first three questions, he/she was told, "Actually, the asterisks did not appear completely randomly throughout the task. Maybe you can tell me a bit about how they appeared," and the interview continued.

Generate task. A second method of testing subjects' awareness of the repeating sequence was the cued-recall test of the sequencethe generate task. The subjects tried to push the key where the asterisk would appear next, instead of responding to the visible asterisk. If the subject anticipated incorrectly, the computer did noth-

Table 2

Interview Questions Asked of Subjects Upon Completion of the Serial Response Time Task

1. What strategy did you use in doing the task?

2. Was there anything you thought about during the task?

3. Did the asterisks seem to appear randomly, or did it ever seem like you could predict where they would appear?

4. Can you tell me anything about the sequence?

5. Did the asterisks appear in a specific repeating sequence, or were some positions more probable after other positions?

6. Did the sequence repeat continuously, or did it come and go?

7. Could you show me as much of the sequence as you can remember, either on the screen or on the response board? ing, and the subject tried a different response. After the correct response, the asterisk disappeared and a new asterisk appeared where the subject had anticipated it. The subject then tried to anticipate the next position in the sequence. The sequence appeared four times.

The subjects were told to emphasize accuracy rather than speed. They were also told that the asterisks would appear in the same repeating sequence that they had seen during the SRT task.

\section{Results}

Response times. RTs from error trials were not included in the analysis. The median RT of each run of 12 responses was calculated, and the mean of the five medians in each block was calculated. RTs and blocks were then converted to a logarithmic scale, and a linear regression across groups was performed (Newell \& Rosenbloom, 1981). The linear fit was excellent $[F(1,176)=$ $17.21, M S_{\mathrm{e}}=0.001, p<.001 ;$ with quadratic and higher order factors combined, $F(8,176)=0.59, M S_{\mathrm{e}}=0.001$, $p>.10]$. A linear regression was calculated for each subject, and the slopes of the fitted lines were compared across subject groups. The data are shown in Figure 1.

There was no significant difference between the HD patients and age-matched control subjects $[t(22)=1.5$, $.10<p<.15$ ], indicating that HD patients and controls learned at the same rate. This analysis must be interpreted with caution, however, because the variances of the slopes were different [HD $=.0223$, control $=.0013, F(11,11)=$ $17.15, p<.001]$ for the two groups as assessed by Paul's rule (Snedecor \& Cochran, 1980). The nonparametric Mann-Whitney test was applied to the slope measure, and it showed a significant difference between groups $(U=$ $32, p<.025$ ).

The critical comparison for sequence learning is performance on the 10th block of trials, when the sequence was removed and the asterisks appeared randomly. A predicted RT for the 10th trial block was calculated for each subject on the basis of the regression line calculated from the first 9 blocks, and that predicted RT was compared with the observed RT, yielding a difference score. The difference scores of $\mathrm{HD}$ patients were significantly smaller than those of the age-matched control subjects $[t(22)=$ $4.33, p<.001]$. Thus, the performance of the HD patients depended less on knowledge of the repeating sequence, in comparison with the performance of the control groups.

Accuracy. The percentage of correct responses during each block of trials was calculated for each subject. The means are shown for subject groups in Table 3.

Across the first nine blocks of trials, an analysis of variance (ANOVA) showed that HD patients were less accurate than controls $\left[F(1,22)=12.86, M S_{\mathrm{e}}=58.45, p<\right.$ $.01]$. The effect of trial block was also significant $\left[F(8,176)=2.09, M S_{\mathrm{e}}=4.71, p<.05\right]$, as was the interaction $\left[F(8,176)=2.77, M S_{\mathrm{e}}=4.71, p<.05\right]$, but follow-up contrasts revealed that no subject group became consistently more or less accurate across trials. These effects appear to be due to random block-by-block variation in the HD subjects' accuracy. 


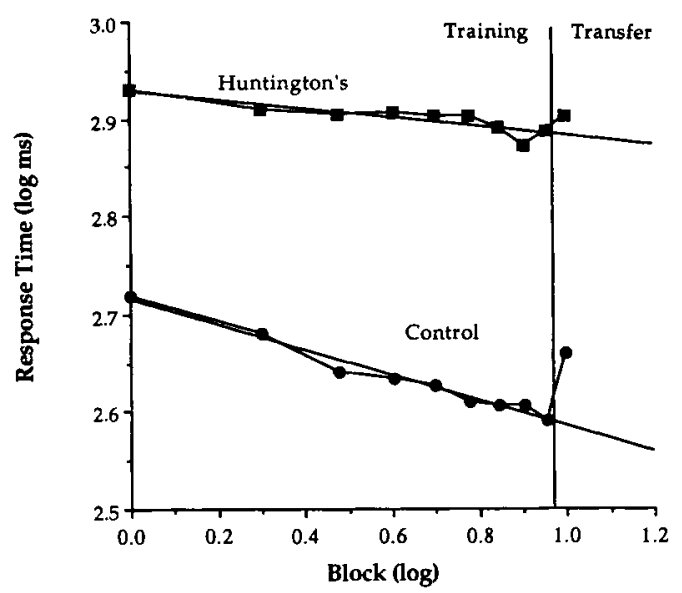

Figure 1. $\log$ transformed response times on the serial response time task at training and transfer, by subject group.

It was expected that subjects might become less accurate in their responses when transferred to the random sequence. Difference scores between Blocks 9 and 10 showed that the control subjects' accuracy was disrupted by transfer more than the HD patients' $[t(22)=2.48, p<.05]$.

Interview and generate task. The experiment was designed to prevent conscious, explicit awareness of the repeating sequence, and that goal was met. Only 1 control subject claimed any awareness of a repeating sequence during the interview. That subject could not describe any portion of the sequence. None of the HD patients showed awareness of the repeating sequence.

Control subjects also performed poorly on the generate task. The generate task was discontinued for the HD patients after several patients became upset when presented with it; they reported feeling anxious because they had no conscious knowledge of the sequence and assumed that this fact reflected on their intellectual decline.

Across the four repetitions of the sequence, the mean percent accuracy of the control subjects was 46.9, 46.3, 42.5, and 43.9. This performance is comparable to that of the naive subjects in Experiment 1 of Willingham et al.

Table 3

Mean Accuracy in the Serial Response Time Task

\begin{tabular}{ccccc}
\hline & \multicolumn{4}{c}{ Group } \\
\cline { 2 - 5 } Trial & \multicolumn{2}{c}{ HD } & \multicolumn{2}{c}{ Control } \\
\cline { 2 - 5 } Block & $M$ & $S D$ & $M$ & $S D$ \\
\hline 1 & 93.3 & 4.8 & 97.2 & 3.6 \\
2 & 92.5 & 4.8 & 99.1 & 1.6 \\
3 & 94.8 & 4.3 & 98.9 & 1.2 \\
4 & 95.5 & 3.8 & 99.0 & 2.1 \\
5 & 94.1 & 4.1 & 98.3 & 2.7 \\
6 & 95.2 & 3.5 & 98.3 & 2.0 \\
7 & 96.2 & 2.2 & 97.5 & 3.0 \\
8 & 95.3 & 3.6 & 97.6 & 1.6 \\
9 & 93.5 & 3.9 & 98.1 & 2.1 \\
10 & 94.3 & 4.4 & 95.7 & 4.3 \\
\hline
\end{tabular}

Note-HD, Huntington's disease.
(1989), whose accuracy level was 42.6 in the first repetition of the sequence. These subjects received no training on the SRT task and were simply asked to perform the generate task.

RT data were not analyzed in this task, because subjects were instructed to take as much time as they liked in making their responses and to emphasize accuracy in their responses.

In summary, the HD patients and control subjects responded more quickly with practice, but the HD patients' rate of improvement was slower. When the repeating sequence was removed and the asterisks appeared randomly, the RTs of control subjects were slowed significantly more than the RTs of the HD patients, indicating that the control subjects learned the sequence to a greater extent than the HD patients did.

\section{EXPERIMENT 2}

HD patients did not learn the sequential aspect of the task in Experiment 1 normally. The goal of Experiment 2 was to test HD patients' ability to learn a motor skill that did not require learning a repeating sequence. We attempted to make this test as similar as possible to the SRT task in Experiment 1.

\section{Method}

The incompatible serial response time task (ISRT) was identical to the SRT task except in the following three ways. First, there was a different stimulus-response mapping. Instead of pushing the key directly below the asterisk that appeared, the subjects pushed the key that was one position to the right of the asterisk that appeared. If the asterisk appeared in the fourth position, the subjects pushed the key on the far left of the response board. Second, the stimuli in the ISRT task did not appear in a repeating sequence as they did in the SRT task. All subjects saw the same random sequence of asterisk positions. Third, the subjects performed only five blocks of the ISRT task.

In the SRT task, the important measure was the RT difference between the sequenced and random trial blocks. In the ISRT task, learning was measured simply by the rate of RT decline. One could include a block of trials at the end of training that called for a different response rule (e.g., push one key to the left of the stimulus), but because some striatal patients might have difficulty switching sets (Cools, van den Bercken, Horstink, van Spaendonck, \& Berger, 1984), their RTs might be slow on this new task-not because they had learned the association, but because it would be difficult to switch from the old response rule to the new one. Such a result would lead to an overestimation of HD learning.

\section{Results}

Two HD patients were removed from the analysis. One had RTs that were more than three standard deviations slower than the mean of the other patients, and 1 had accuracy scores that were more than three standard deviations lower than those of the other patients.

Response times. The statistical analysis was identical to the analysis performed on the SRT data.

RTs were transformed and analyzed as in Experiment 1 [linear component of the regression, $F(1,84)=16.0$, 
$M S_{\mathrm{e}}=.002, p<.001 ;$ quadratic and higher, $F(3,84)$ $\left.=2.56, M S_{\mathrm{e}}=.002, .05<p<.10\right]$. The transformed data are shown in Figure 2.

There was no significant difference between the HD patients and the control group $[t(20)=.68, p>.20]$. This $t$ test cannot be interpreted unambiguously, however, because the variances of slopes of the HD patients $(0.0185)$ and the age-matched control subjects (0.004) were different, as assessed by Paul's rule (Snedecor \& Cochran, 1980). The nonparametric Mann-Whitney test was also used, and it showed that the slopes did not differ ( $U=$ $63, p>.20$ ).

Accuracy. The accuracy data are shown in Table 4. The HD subjects responded less accurately $[F(1,20)=$ $\left.7.09, M S_{\mathrm{e}}=289.98, p<.025\right]$. Neither group changed accuracy across blocks $\left[F(4,80)=0.283, M S_{\mathrm{e}}=90.98\right.$, $p>.20]$, and the interaction of the subject and block variables was just short of statistical significance $[F(4,80)=$ $\left.2.20, M S_{\mathrm{e}}=90.98, p=.076\right]$. A glance at Table 4 indicates that the interaction is likely due to the improved accuracy of the HD patients' responses across blocks, whereas the control subjects' accuracy improved less, probably because of a ceiling effect; the control subjects responded with very high accuracy from the beginning of the task. The important point is that the HD subjects' normal improvement in the RT measure was not due to their trading speed for accuracy.

\section{EXPERIMENT 3}

HD patients did not learn the repeating sequence in Experiment 1, but learned the incompatible mapping in Experiment 2. The goal of Experiments 3 and 4 was to extend this finding to a different paradigm-maze learning. Again, we used one task in which the bulk of the learning would involve acquiring a new perceptual-motor mapping, and a second task in which part of the learning would be based on a repetitive sequence of movements.

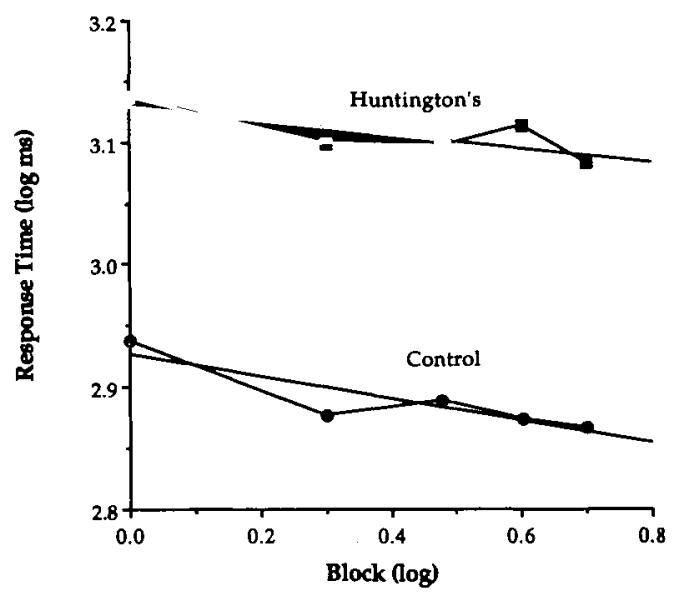

Figure 2. Log transformed response times on the incompatible serial response time task at training and transfer, by subject group.
Table 4

Mean Accuracy in the Incompatible Serial Response Time Task

\begin{tabular}{ccccc}
\hline & \multicolumn{4}{c}{ Group } \\
\cline { 2 - 5 } Trial & \multicolumn{2}{c}{ HD } & \multicolumn{2}{c}{ Control } \\
\cline { 2 - 5 } Block & $M$ & $S D$ & $M$ & $S D$ \\
\hline 1 & 83.3 & 11.0 & 94.9 & 5.0 \\
2 & 81.2 & 15.1 & 95.8 & 4.3 \\
3 & 84.7 & 8.2 & 95.5 & 5.8 \\
4 & 87.0 & 8.5 & 94.7 & 6.9 \\
5 & 88.0 & 7.2 & 95.2 & 4.9 \\
\hline
\end{tabular}

Note-HD, Huntington's disease.

In Experiment 3, the subjects used a computer mouse to navigate a stepping-stone maze. They saw the same maze across trials and so could learn the particular sequence of steps through the maze, although they were not instructed to do so. We predicted, however, that the subjects would not acquire knowledge specific to the maze, because attention would be allocated to learning to manipulate the mouse, and sequence learning appears to require attention (Cohen, Ivry, \& Keele, 1990). To test this prediction, a new maze was introduced after training to evaluate transfer. We also predicted that the HD patients, because they were not required to learn a repeating sequence of movements, would show normal acquisition of the skill; they would learn the stimulus-response mapping necessary to manipulate the mouse.

\section{Method}

Each subject saw a $10 \times 10$ array of circles like that shown in Figure 3. Each circle had a diameter of 30 pixels, or approximately $1.1 \mathrm{~cm}$.

The subjects were told that the dark circles constituted a path through the maze, and they were asked to traverse the maze from start to finish, which constituted one trial. The subject moved the mouse with his/her preferred hand, pushing the mouse button when the arrow-shaped cursor was in the next darkened circle--whereupon that circle turned white. The "hot spot" of the cursor was the tip of the arrow, and the workings of the "hot spot" were explained to the subjects.

The mouse was manipulated on a Mousetrak mousepad measuring $24 \times 27.5 \mathrm{~cm}$, oriented vertically. At the end of each trial, the experimenter repositioned the cursor so that it was in the center of the first darkened circle and repositioned the mouse so that it was in the lower left corner of the mousepad. None of the subjects had used a computer mouse before.

Errors and reaction times were recorded, reaction time being defined as response-to-response time, measured by the system clock to the nearest $16.7 \mathrm{msec}$. The clock was started when the subject made the first response of a trial. Errors were signaled by a 120msec tone.

The subjects were trained on the same maze for 20 trials and then transferred to a new maze for 5 trials. The transfer maze had the same number of steps through the maze (25), the same number of turns (12), and the same start and finish points as did the training maze. There was a 2-min rest break after 10 trials and between training and transfer. Three different maze paths were used, and the subjects were randomly assigned one path for training and one for transfer.

The experimenter explained the function of the mouse before training began, and the subject was allowed to manipulate the mouse for approximately $30 \mathrm{sec}$. Mouse tracking was set at the slowest speed. 


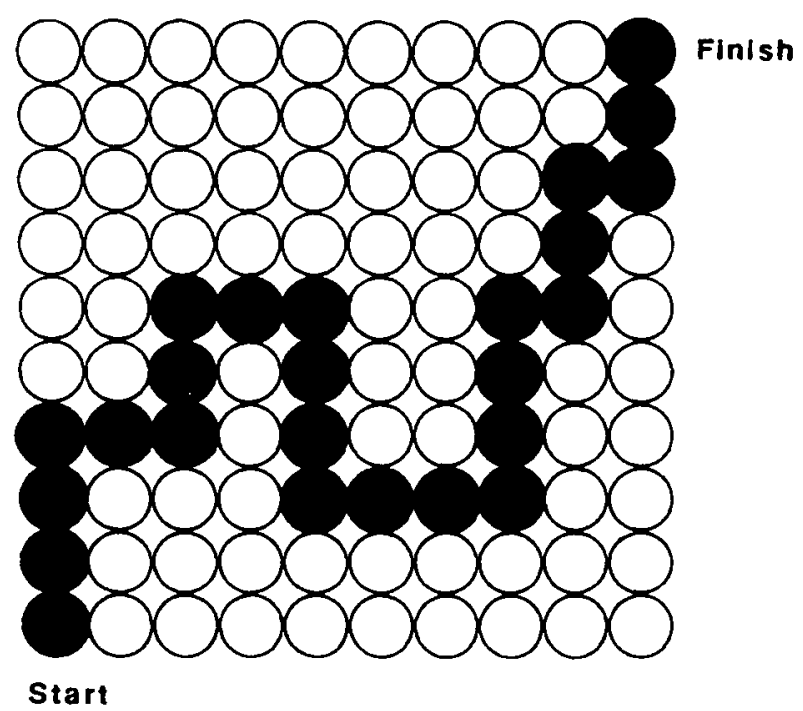

Figure 3. Stepping stone maze as it appeared on the computer screen.

\section{Results}

The particular maze path was not a significant factor in any analysis and will not be discussed further.

Training. The HD patients improved their RTs in traversing the maze at the same rate as the control subjects did during training.

The 24 RTs were averaged for each trial. These mean RTs and the trial numbers were transformed as in previous experiments [linear fit, $F(1,460)=46.14, M S_{\mathrm{e}}=$ $0.079, p<.001$; quadratic and higher order factors, $\left.F(18,460)=.079, M S_{\mathrm{e}}=0.079, p>.10\right]$. The transformed data for each group are shown in Figure 4.

The HD patients learned at the same rate as age-matched control subjects did $[t(22)=0.24, p>.10]$.

The subjects were told to respond as quickly as possible without making errors, and there was no difference in the accuracy scores across trials $\left[F(1,21)=1.54, M S_{\mathrm{e}}=41.4\right.$, $p>.20]$ or between subject groups $[F(19,399)=1.19$, $\left.M S_{\mathrm{e}}=3.22, p>.20\right]$. Nor was there any interaction $\left[F(19,399)=0.69, M S_{\mathrm{e}}=3.22, p>.20\right]$.

Transfer. The transfer scores of $1 \mathrm{HD}$ patient were lost due to a computer failure.

Each group's mean observed RTs for Trials 21-25 are shown in Figure 4, along with the trend lines that were used to calculate the predicted values of Trials 21-25. Predicted and observed performance on each of Trials 21-25 were averaged, yielding one difference score for each subject. These scores did not differ for HD patients and agematched control subjects $[t(20)=0.88, p>.10]$. An analysis of the first transfer trial alone showed that HD and age-matched control subjects were affected similarly by transfer to the new maze $[t(20)=1.60, p>.10]$. The subjects did not make more errors when transferred to the new maze $\left[F(1,21)=0.34, M S_{\mathrm{e}}=1.11, p>.20\right]$, and this figure did not vary by subject group $[F(1,21)=$ $\left.0.34, M S_{\mathrm{e}}=1.11, p>.20\right]$.
In summary, HD patients showed normal learning of the skill. The skill is general to learning to manipulate the mouse, and is not specific to movements necessary to navigate the maze. Although both subject groups could have acquired maze-specific knowledge, neither did.

\section{EXPERIMENT 4}

The results of Experiment 3 supported the hypothesis that HD patients can learn skills that require learning a new perceptual-motor mapping. The same maze task was used in Experiment 4, but the subjects were required to respond via keypresses. We predicted that control subjects would no longer need to allocate attention to learning a new perceptual-motor mapping and so would learn part or all of the repetitive sequence that was necessary for navigating the maze. We therefore predicted that $\mathrm{HD}$ patients would be impaired relative to control subjects.

\section{Method}

The subjects used a response board with four keys arranged in a diamond to traverse the maze. They used the preferred hand to push the top key to move upward in the maze, the bottom key to move downward, and the left and right keys to move in those directions. The cursor was not visible. When the correct key was pushed, the darkened circle became white. The subjects could keep track of their progress in the maze by means of the lightened circles. All other aspects of the method were as in Experiment 3.

\section{Results}

The particular maze path used was not a significant factor in any analysis and will not be discussed further.

Training. The mean RTs and the trial numbers were transformed as in previous experiments [linear fit, $F(1,46)$ $=21.979, M S_{\mathrm{e}}=0.048, p<.001 ;$ quadratic and higher order factors, $F(18,461)=1.56, M S_{\mathrm{e}}=0.048, p>.10 \mathrm{~J}$. The transformed data for each group are shown in Figure 5.

Comparisons of the slopes show that the HD patients and control subjects improved their RTs at the same rate $[t(22)=1.61, p>.20]$. The lack of difference in the RTs may be due to the very slow responses of the HD

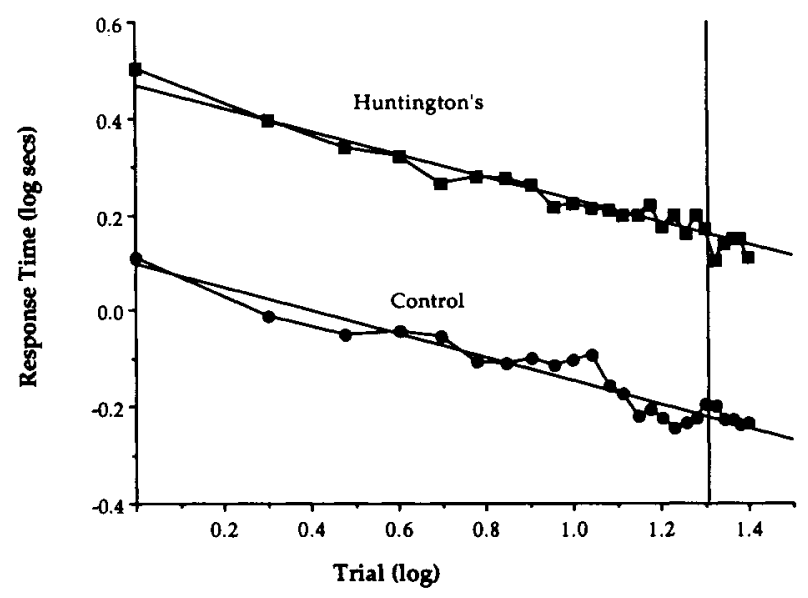

Figure 4. Log transformed response times on the mouse maze at training and transfer, by subject group. 


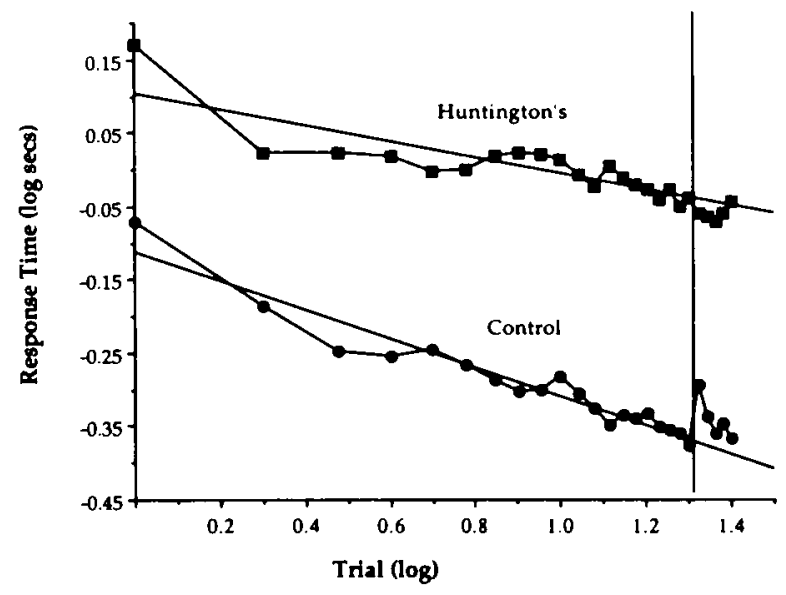

Figure 5. Log transformed response times on the key maze at training and transfer, by subject group.

subjects on the first trial; the other trials adhere to a linear trend, but the first trial is considerably slower than the trend indicates it should be. There were no practice trials for the task, and it is possible that the HD patients did not fully understand the task from the verbal instructions and essentially used the first trial as practice during which they came to understand the task. Indeed, the HD patients improved their RTs from Trial 1 to Trial 2 considerably more than the control subjects $[t(22)=3.02, p<.01]$, but they improved considerably less than the controls from Trial 2 to Trial $20[t(22)=3.58, p<.01]$. If slopes are calculated from Trials 2-20 only, the HD patients show slower learning than age-matched control subjects $[t(22)=$ $3.221, p<.01]$.

The HD patients were significantly less accurate than controls $\left[F(1,22)=6.54, M S_{\mathrm{e}}=24.07, p<.025\right]$, but both subject groups made fewer errors across trials (i.e., as training progressed) $\left[F(19,418)=3.64, M S_{\mathrm{e}}=1.61, p<.01\right]$. Both groups reduced their errors across trials to the same extent $\left[F(19,418)=1.96, M S_{\mathrm{e}}=1.61, p>.20\right]$.

Transfer. The transfer scores of 2 HD patients were lost because of computer failure.

Transfer was assessed by using performance on the first 20 trials (training) to predict performance on the 5 transfer trials. Predicted and observed performance was compared on each of Trials 21-25, yielding five difference scores.

The average difference scores for the HD patients and control subjects did not differ $[t(20)=0.55, p>.10]$. The subjects did not make more errors when transferred to the new maze $\left[F(1,20)=1.67, M S_{\mathrm{e}}=4.93, p>.20\right]$, and this figure did not vary by subject group $[F(1,20)=$ $\left.0.67, M S_{\mathrm{e}}=3.44, p>.20\right]$.

The transfer data were also analyzed with the first training trial omitted. In this analysis, the average difference scores for the HD patients and control subjects differed on the first transfer trial $[t(20)=2.147, p<.05]$. They did not on the second trial $[t(20)=0.584, p>.10]$.
The results of these analyses show that control subjects learned faster than the HD patients during the training trials. The learning of the HD patients was not specific to the maze they were trained on; they showed no decrement at transfer. The control subjects, however, did show a slowing of RT when transferred to a new maze, although the effect disappeared after one trial.

\section{DISCUSSION}

The purpose of these experiments was to test whether HD patients show a dissociation in learning motor skills that entail a repeating sequence of movements and skills that require learning a new stimulus-response mapping. The results indicate such a dissociation.

In Experiment 1, HD patients were impaired in learning the SRT task. Patients improved their RTs during training less than controls, and they did not benefit from learning the sequential nature of the stimuli, which was reflected in their performance when transferred to random stimuli. In Experiment 2, no sequence was available to be learned, but a new mapping of stimuli and responses was required. HD patients showed normal learning on this task. This dissociation pattern was not changed when the 2 HD patients removed from the analysis in Experiment 2 were removed from the analysis of Experiment 1.

In Experiment 3, HD patients learned the mouse maze normally. None of the subjects showed learning that was specific to the particular maze used in training. In Experiment 4 , the HD patients improved their RTs less than control subjects during training, and their performance showed no decrement when they were transferred to a new maze. The control subjects did show a decrement at transfer, indicating that their learning during training included some knowledge specific to that maze.

Previous experiments have demonstrated motor skill learning deficits in PD patients (Harrington et al., 1990) and in HD patients (Heindel et al., 1988; Knopman \& Nissen, 1991) but have not predicted which motor skills (if any) HD patients might learn normally.

\section{Comparison With Previous Findings}

There are some reports of normal learning of motor skills that entail a repetitive movement. While most researchers report that $P D$ patients are impaired in tracking a predictable target, several researchers have reported normal performance by PD patients in these tasks (Bloxham, Mindel, \& Frith, 1984; Bondi \& Kaszniak, 1991; Day, Dick, \& Marsden, 1984). However, there are difficulties with each of these studies. First, all of these studies tested Parkinson's disease patients who were on medication, which can have a profound impact on motor preparation (Pullman, Watts, Juncos, Chase, \& Sanes, 1988). Furthermore, Bloxham et al. (1984) used only patients whose absolute performance on a random tracking task could be matched to that of control subjects; perhaps only PD patients who were exceptionally good at track- 
ing were tested. Day et al. (1984) report that PD patients benefited from the predictability of the track; they did in their study, but the critical question is whether they benefit as much as normal subjects benefit. That comparison in their data showed PD patients benefiting less, although the statistical comparison just missed significance $(p=$ .08). Bondi and Kaszniak (1991) reported normal learning on pursuit rotor by PD patients, but subjects responded with a computer mouse, not a stylus. It is possible that all subjects were not really learning a repetitive track per se, but were learning how to use the mouse effectively, as in Experiment 3 reported here. That subjects in their study were unfamiliar with the workings of the mouse is indicated by very poor initial performance (time on target was less than $10 \%$ even though target speed was $14 \mathrm{rpm}$ or slower).

\section{What Underlies the Dissociation?}

First, no evidence supports the hypothesis that medication was a factor in the results. The pattern of data reported is consistent across the subjects who were taking various medications, as well as the subjects who were not taking medication.

There is evidence that the basal ganglia play a role in the perception and use of egocentric space (Brouwers, Cox, Martin, Chase, \& Fedio, 1984; Bylsma, Brandt, \& Strauss, 1992; Cook \& Kesner, 1988; Potegal, 1971), but it seems doubtful that spatial deficits mediated HD patients' failure to learn some tasks in this study. HD patients learned the nonrepetitive tasks that seem to make equal demands on the use of spatial information. Why should the ISRT task, which HD patients learn normally, be less spatially demanding than the SRT task, which they do not?

One might also propose that the HD deficit is not a motor deficit, but rather a cognitive problem; indeed, striatal patients do have difficulty with cognitive tasks that require planning and sequencing (Mendez, Adams, \& Lewandowski, 1989; Sullivan, Sagar, Gabrieli, Corkin, \& Growdon, 1985). This interpretation seems particularly plausible because HD is commonly thought to affect primarily the caudate nucleus rather than the putamen, and the caudate is part of a basal-ganglia-thalamo-cortical loop with the dorsolateral prefrontal cortex, which might mediate more cognitive functions. But $\mathrm{HD}$ affects not just the caudate but also the putamen in its early stages (Harris et al., 1992), and the putamen projects primarily to the supplementary motor area (SMA). Previous data are equivocal regarding whether the skill learning deficit is primarily cognitive or motor. Some researchers report a significant correlation between ratings of dementia and skill impairment (Heindel et al., 1989); others do not (Harrington et al., 1990; Heindel et al., 1988). Performance on our tasks was unrelated to scores on the Blessed Dementia Scale (all $r \mathrm{~s}<.42$, all $p$ s $>.10$ ). We cannot emphasize these correlations, because the small number of patients in this study does not yield much power for correlational analyses. Furthermore, we selected early HD patients, so the range of performance on the standardized tests was small. Some more specific hypotheses about cognitive deficits may, however, be addressed.

Switching behavioral sets is hypothesized to be impaired in PD (Bowen, Burns, Brady, \& Yahr, 1976; Cools et al., 1984; but see Brown \& Marsden, 1988) but seems not to underlie HD impairment in the tasks reported here. In Experiment 1, for example, subjects were not asked to shift sets. Indeed, they remained unaware of the change from patterned to random stimuli.

A second cognitive process thought to be impaired in HD is attention. Other experiments with normal control subjects have indicated that learning motor sequences demands attention (Cohen et al., 1990; Curran \& Keele, 1993). Attentional distraction retards learning even when learning takes place outside of awareness, as in the SRT task. It is possible that, because of their motor control difficulties, HD patients must attend so closely to generating responses that attentional resources are not available for sequence learning. There have also been some suggestions that HD patients in fact have impoverished attentional resources (Brown \& Marsden, 1991; Singh, Gabrieli, \& Goetz, 1992). We believe that this account of the failure to learn sequencing tasks is plausible and bears further study. Still, we think it is less likely than an explanation in which the striatum plays some role in the sequencing of motor acts. A wealth of evidence indicates that, in simple motor control situations that demand very little attention, HD and PD subjects are impaired in motor sequencing. It seems sensible, therefore, to interpret the data presented here in light of those findings; HD patients are impaired in learning motor skills that require repetitive movements because the striatum is critical to effective sequencing.

\section{The Striatum and Sequencing}

There are at least three ways in which the striatum may be involved in sequence learning. First, there may be two motor skill systems: one that is responsible for acquiring repetitive sequences of movement, and one that is responsible for learning new relationships between stimuli or cues and the appropriate motor responses. Although the data presented here are consistent with such a view, they certainly do not compel it. Second, it is possible that the striatum is involved in sequencing, but plays no role in the improvement of performance; because sequencing is compromised in $\mathrm{HD}$, it appears that these patients have a skill learning deficit particular to motor skills requiring sequencing. One recent study has suggested that this view is unlikely to be accurate. Grafton et al. (1992) investigated regional cerebral blood flow in normal subjects during the pursuit rotor tracking task and found consistent changes in the SMA associated with learning. The SMA was also strongly associated with executing the movements necessary to complete the task. As the authors suggested, there may not be a structure or set of structures that is responsible for motor skill in the way that the hippocampus and related structures subserve explicit 
memory. It may be that skill learning occurs as the structures that underlie motor control functions become tuned to particular tasks. The plasticity necessary for motor skill resides in the same structures that are necessary for motor control, so HD patients would not have a primary problem in motor control that leads to an apparent problem in motor skill; control and skill are subserved by the same brain structures.

A final possibility is that the problem in sequencing is secondary to a more general problem in open-loop movements-that is, movements without strong perceptual cues. Patients may be particularly dependent on perceptual feedback (Cooke, Brown, \& Brooks, 1978; Flowers, 1978; Heindel et al., 1988). Showing robust sequence learning may require initiating responses before there is information in the environment directing the response. Some aspect of programming begins in control subjects prior to the appearance of the stimulus.

\section{The Striatum and Other Motor Structures}

The anatomic connections of the striatum are consistent with its putative roles as a sequencer of motor responses and a generator of open-loop movements. The somatosensory cortex projects to the striatum heavily and widely (Graybiel \& Ragsdale, 1979; Kunzle, 1977), and it may be the only bilateral cortical projection to the striatum (Nauta \& Domesick, 1979). The primary target of this circuit (via the thalamus) is the SMA, which has been implicated in the sequencing of motor acts (Dick, Benecke, Rothwell, Day, \& Marsden, 1986; Gaymard, Pierrot-Deseilligny, \& Rivaud, 1990; Mushiake, Inase, \& Tanji, 1991; Passingham, 1987). Somatosensory information may be important in building a representation of the body's position in space, which would be used to guide rapid movements; visual feedback regarding body position may not be used on line to direct movement, because it is relayed too slowly (Hollerbach, 1982).

Our HD patients learned a new visuomotor mapping in Experiment 2, suggesting that such learning does not rely on the striatum. The premotor cortex has been implicated in visuomotor associations (Halsband \& Freund, 1990; Passingham, 1985, 1988). Although the striatum does project to the premotor cortex via pallido-thalamic projections (Schell \& Strick, 1984), pallidal, nigral, and cerebellar projections to the motor cortex via the thalamus remain separate (Jones, 1987). They may subserve separate functions and may be differentially compromised during the various stages of HD. HD patients also learned a novel tracing skill (use of the mouse) in Experiment 3, indicating that this operation was spared in these patients with early $\mathrm{HD}$. The lateral cerebellum may be critical for learning these tracing tasks (Sanes, Dimitrov, \& Hallett, 1990).

In summary, there is some evidence that sequencing and visuomotor integration represent brain systems that are instantiated in different neural structures and can operate independently; there is also evidence that the striatum plays a role in generating movements in the absence of visual cues. The present data are consistent with both views, but we cannot rule out interpretations based on attention. The particular mechanisms underlying intact visuomotor integration and impaired sequence learning in HD must await further investigation. The present studies were designed to demonstrate that these two types of motor skill learning are dissociable in HD.

\section{REFERENCES}

Benton, A. L. (1950). A multiple choice type of the visual retention test. Archives of Neurology \& Psychiatry, 64, 699-707.

Benzing, W. C., \& SQuire, L. R. (1989). Preserved learning and memory in amnesia: Intact adaptation-level effects and learning of stereoscopic depth. Behavioral Neuroscience, 103, 538-547.

Blessed, G., Tomlinson, B. E., \& Roth, M. (1968). The association between quantitative measures of dementia and senile change in the cerebral gray matter of elderly subjects. British Journal of Psychiatry, 114, 797-811.

Bloxham, C. A., Mindel, T. A., Frith, C. D. (1984). Initiation and execution of predictable and unpredictable movements in Parkinson's disease. Brain, 107, 371-384.

Bond, M. W., Kaszniak, A. W. (1991). Implicit and explicit memory in Alzheimer's disease and Parkinson's disease. Journal of Clinical \& Experimental Neuropsychology, 13, 339-358.

Bowen, F. P., Burns, M. M., Brady, E. M.. Yahr, M. D. (1976). A note on alterations of personal orientation in parkinsonism. Neuropsychologia, 14, 454-465.

Brooks, D. N., BADDEley. A. (1976). What can amnesic patients learn? Neuropsychologia, 14, 111-122.

Brouwers, P.. Cox, C., Martin, A., Chase, T., Fedio, P. (1984). Differential perceptual-spatial impairment in Huntington's and Alzheimer's dementia. Archives of Neurology, 41, 1073-1076.

Brown, R. G., MArsden, C. D. (1988). Internal versus external cues and the control of attention in Parkinson's disease. Brain, 111 , 323-345.

Brown, R. G., MARSDEN, C. D. (1991). Dual task performance and processing resources in normal subjects and patients with Parkinson's disease. Brain, 114, 215-231

Butters, N., Wolfe, J., Granholm, E.. \& Martone, M. (1986). An assessment of verbal recall, recognition and fluency abilities in patients with Huntington's disease. Cortex, 22, 11-32.

Brisma, F. W., Brandt, J., Strauss, M. E. (1992). Personal and extrapersonal orientation in Huntington's disease patients and those at risk. Cortex, 28, 113-122.

Cohen, A., IVrY, R. I., \& KeELe, S. W. (1990). Attention and structure in sequence learning. Journal of Experimental Psychology: Learning, Memory, \& Cognition, 16, 17-30.

Cohen, N. J., \& SQuire, L. R. (1980). Preserved learning and patternanalyzing skill in amnesia: Dissociation of knowing how and knowing that. Science, 210, 207-210.

COOK, D., KESNER, R. P. (1988). Caudate nucleus and memory for egocentric localization. Behavioral \& Neural Biology, 49, 332-343.

CoOKe, J. D., Brown, J. D.. \& Brooks, V. B. (1978). Increased dependence on visual information for movement control in patients with Parkinson's disease. Canadian Journal of Neurological Sciences, 5 , 413-415.

Cools, A. R., van den Bercken, J. H. L., Horstink, M. W. I., van Spaendonck, K. P. M., \& Berger, H. J. C. (1984). Cognitive and motor shifting aptitude disorder in Parkinson's disease. Journal of Neurology, Neurosurgery \& Psychiatry, 47, 443.

Corkin, S. (1968). Acquisition of motor skill after bilateral medial temporal lobe excision. Neuropsychologia, 6, 255-265.

Curran, T., \& KeEle, S. W. (1993). Attentional and nonattentional forms of sequence learning. Journal of Experimental Psychology: Learning, Memory, \& Cognition, 19, 188-202.

DaY, B. L., Dick, J. P. R., Marsden, C. D. (1984). Patients with Parkinson's disease can employ a predictive motor strategy. Journal of Neurology, Neurosurgery, \& Psychiatry, 47, 1299-1306. 
Dick, J. P. R., Benecke, R., Rothwell, J. C., Day, B. L., MarsDEN, C. D. (1986). Simple and complex movements in a patient with infarction of the right supplementary motor area. Movement Disorders, 1, 255-266.

FLOWERS, K. (1978). Some frequency response characteristics of parkinsonism on pursuit tracking. Brain, 101, 19-34.

Frith, C. D., Bloxham, C. A., \& CARpenter, K. N. (1986). Impairments in the learning and performance of a new manual skill in patients with Parkinson's disease. Journal of Neurology, Neurosurgery, \& Psychiatry, 49, 661-668.

Gaymard, B., Pierrot-Deseilligny, C., \& Rivaud, S. (1990). Impairment of sequences of memory-guided saccades after supplementary motor area lesions. Annals of Neurology, 28, 622-626.

Grafton, S. T., Mazziotta, J. C., Presty, S., Friston, K. J., Frackowiak, R. S. J., \& Phelps, M. E. (1992). Functional anatomy of human procedural learning determined with regional cerebral blood flow and PET. Journal of Neuroscience, 12, 2542-2548.

Graybiel, A. M., \& Ragsdale, C. W., Jr. (1979). Fiber connections of the basal ganglia. Progress in Brain Research, 51, 239-283.

Halsband, U., \& Freund, H. (1990). Premotor cortex and conditional motor learning in man. Brain, 113, 207-222.

Harrington, D. L., Haaland, K. Y., Yeo, R. A., \& Marder, E. (1990). Procedural memory in Parkinson's disease: Impaired motor but not visuoperceptual learning. Journal of Clinical \& Experimental Neuropsychology, 12, 323-339.

harris, G. J., Pearlson, G. D., Peyser, C. E., Aylward, E. H., Roberts, J., Barta, P. E., Chase, G. A., \& Folstein, S. E. (1992). Putamen volume reduction on magnetic resonance imaging exceeds caudate changes in mild Huntington's disease. Annals of Neurology, 31, 69-75.

Heindel, W. C., Butters, N., \& Salmon, D. P. (1988). Impaired learning of a motor skill in patients with Huntington's disease. Behavioral Neuroscience, 102, 141-147.

Heindel, W. C., Salmon, D. P., Shults, C. W., Walicke, P. A., \& BUTTERS, N. (1989). Neuropsychological evidence for multiple implicit memory systems: A comparison of Alzheimer's, Huntington's, and Parkinson's disease patients. Journal of Neuroscience, 9, 582-587.

HollerbaCh, J. M. (1982). Computers, brains, and the control of movement. Trends in Neurosciences, 5, 189-192.

JoNES, E. G. (1987). Ascending inputs to, and internal organization of, cortical motor areas. In G. Bock, M. O'Connor, \& J. Marsh (Eds.), Motor areas of the cerebral cortex (pp. 21-35). New York: Wiley.

Knopman, D., \& Nissen, M. J. (1991). Procedural learning is impaired in Huntington's disease: Evidence from the serial reaction time task. Neuropsychologia, 29, 245-254.

KUNZLE, H. (1977). Projections from the primary somatosensory cortex to basal ganglia and thalamus in the monkey. Experimental Brain Research, 30, 481-492.

LEZAK, M. D. (1976). Neuropsychological assessment. New York: Oxford University Press.

Mendez, M. F., Adams, N. L., \& Lewandowski, K. S. (1989). Neurobehavioral changes associated with caudate lesions. Neurology, 39, 349-354.

MiLNER, B. (1962). Les troubles de la memoire accompagnant des lesions hippocampiques bilaterales. In Physiologie de lhippocampe (pp. 257-272). Paris: Centre National de la Recherche Scientifique.

Mishkin, M., Malamut, B., \& Bachevalier, J. (1984). Memories and habits: Two neural systems. In G. Lynch, J. McGaugh, \& N. Weinberger (Eds.), Neurobiology of learning and memory (pp. 6577). New York: Guilford.

Mushiake, H., INASE, M., \& TANJI, J. (1991). Neuronal activity in the primate premotor, supplementary, and precentral motor cortex during visually guided and internally determined sequential movements. Journal of Neurophysiology, 65, 705-718.

Myers, R. H., Von Sattell, J. P., Stevens, T. J., Cupples, L. A., Richardson, E. P., Martin, J. B., \& Bird, E. D. (1988). Clinical and neuropathological assessment of severity in Huntington's disease. Neurology, 38, 341-347.
National Institutes of Health (1988). Medical history (Part 2). Baltimore, MD: National Institute of Aging, Gerontology Research Center.

Nauta, W. J. H., Domesick, V. B. (1979). The anatomy of the extrapyramidal system. In K. Fuxe \& D. B. Calne (Eds.), Dopaminergic ergot derivatives and motor function (pp. 3-22). New York: Pergamon.

Newell, A. M., \& Rosenbloom, P. S. (1981). Mechanisms of skill acquisition and the law of practice. In J. R. Anderson (Eds.), Cognitive skills and their acquisition (pp. 1-55). Hillsdale, NJ: Erlbaum.

Nissen, M. J., \& Bullemer, P. (1987). Attentional requirements of learning: Evidence from performance measures. Cognitive Psychology, 19, 1-32.

Nissen, M. J., Willingham, D. B., \& Hartman, M. (1989). Explicit and implicit remembering: When is learning preserved in amnesia? Neuropsychologia, 27, 341-352.

Passingham, R. E. (1985). Premotor cortex: Sensory cues and movement. Behavioural Brain Research, 18, 175-185.

Passingham, R. E. (1987). Two cortical systems for directing movement. In G. Bock \& J. Marsh (Eds.), Motor areas of the cerebral cortex (pp. 151-164). Chichester, U.K.: Wiley.

Passingham, R. E. (1988). Premotor cortex and preparation for movement. Experimental Brain Research, 70, 590-596.

Potegal, M. (1971). A note on spatial-motor deficits in patients with Huntington's disease: A test of a hypothesis. Neuropsychologia, 9, 233-235.

Pullman, S. L., Watts, R. L., Juncos, J. L., Chase, T. N., \& Sanes, J. N. (1988). Dopaminergic effects on simple and choice reaction time performance in Parkinson's disease. Neurology, 38, 249-254.

Robertson, C., \& Flowers, K. A. (1990). Motor set in Parkinson's disease. Journal of Neurology, Neurosurgery, \& Psychiatry, 53, 583-592.

Sanes, J. N., Dimitrov, B., \& Hallett, M. (1990). Motor learning in patients with cerebellar dysfunction. Brain, 113, 103-120.

SCHELL, G. R., \& STRICK, P. L. (1984). The origin of thalamic inputs to the arcuate premotor and supplementary motor areas. Journal of Neuroscience, 4, 539-560.

Shimamura, A. P. (1986). Priming effects in amnesia: Evidence for a dissociable memory function. Quarterly Journal of Experimental Psychology, 38A, 619-644.

Shoulson, I., \& FAHN, S. (1979). Huntington's disease: Clinical care and evaluation. Neurology, 29, 1-3.

Singh, J., Gabrieli, J. D. E., \& Goetz, C. G. (1992). Impairment of working memory in patients with Huntington's disease. Neurology, 42(Suppl. 3), 280.

Snedecor, G. W., \& Cochran, W. G. (1980). Statistical methods (7th ed.). Ames, IA: Iowa State University Press.

Soliveri, P., Brown, R. G., Jahanshahi, M., \& Marsden, C. D (1992). Effect of practice on performance of a skilled motor task in patients with Parkinson's disease. Journal of Neurology, Neurosurgery, \& Psychiatry, 55, 454-460.

SQuire, L. R., \& Zola-Morgan, S. (1991). The medial temporal lobe memory system. Science, 253, 1380-1386.

Sullivan, E. V., Sagar, H. J., Gabrieli, J. D. E., Corkin, S., \& Growdon, J. H. (1985). Sequencing deficits in Parkinson's disease. Journal of Clinical \& Experimental Neuropsychology, 7, 160.

WECHSLER, D. (1981). Wechsler Adult Intelligence Scale-Revised. San Antonio, TX: Psychological Corporation.

Weiner, M. J., Hallett, M., \& Funkenstein, H. H. (1983). Adaptation to lateral displacement of vision in patients with lesions of the central nervous system. Neurology, 33, 766-772.

Willingham, D. B., Nissen, M. J., \& Bullemer, P. (1989). On the development of procedural knowledge. Journal of Experimental Psychology: Learning, Memory, \& Cognition, 15, 1047-1060.

(Manuscript received November 16, 1992; revision accepted for publication April 14, 1993.) 